03,05, 12

\title{
Проявление эффектов магнитного упорядочения в проводимости и намагниченности полупроводниковых гетероструктур на основе GaAs при изменении концентрации дельта-слоя примесей марганца
}

\author{
(C) К.Д. Моисеев ${ }^{1}$, Ю.А. Кудрявцев ${ }^{2}$, Т.Б. Чарикова ${ }^{3,4}$, А.М. Луговых ${ }^{3}$, \\ Т.Е. Говоркова ${ }^{3}$, В.И. Окулов ${ }^{3,4}$ \\ ${ }^{1}$ Физико-технический институт им. А.Ф. Иоффре Российской академии наук, \\ Санкт-Петербург, Россия \\ ${ }^{2}$ Национальный политехнический институт - СИНВЕСТАВ, \\ Мехико, Мексика \\ ${ }^{3}$ Институт физики металлов УрО РАН, \\ Екатеринбург, Россия \\ ${ }^{4}$ Уральский федеральный университет им. Б.Н. Ельцина, \\ Екатеринбург, Россия \\ E-mail: mkd@iropt2.ioffe.ru
}

(Поступила в Редакцию 25 января 2018 г.

В окончательной редакции 29 мая 2018 г.)

На основе анализа магнитополевых и температурных зависимостей, гальваномагнитных эффектов и намагниченности проведено исследование характерных проявлений магнитного упорядочения и проводимости в полупроводниковых гетероструктурах с квантовой ямой $\mathrm{GaAs}: \mathrm{Be} / \mathrm{Ga}_{0.84} \mathrm{In}_{0.16} \mathrm{As} / \mathrm{GaAs}$ и $\delta$-слоями марганца различной толщины (0.4-2 монослоя). Наблюдалась аномальная зависимость проводимости от концентрации атомов марганца в $\delta$-слое, обусловленная сильным рассеянием носителей заряда в структурах с низким содержанием магнитных примесей. Магнитные свойства гетероструктур содержали прямые свидетельства магнитного упорядочения примесной системы (насыщение и гистерезис намагниченности, проявление закона Кюри-Вейса при повышении температуры). Параметры магнитной подсистемы позволили выявить различный характер упорядочения систем с разной концентрацией магнитной примеси. Было показано, что изменение концентрации примеси $\mathrm{Mn}$ в $\delta$-слое существенно влияет на проводящие свойства и магнетизм исследуемых структур.

Работа выполнена в рамках государственного задания по теме „Электрон“ № AAAA-A18-118020190098-5 и проекта № 18-10-2-6 Программы УрО РАН при поддержке РФФИ (грант № 18-02-00192).

DOI: $10.21883 /$ FTT.2018.12.46720.022

\section{1. Введение}

Достижения исследований магнитного упорядочения в разбавленных магнитных полупроводниках ([1-3] и ссылки в них) при распространении на область физики полупроводниковых гетероструктур подвергаются определенной модификации. Это вызвано проблемами, связанными с тем фактом, что в гетероструктурах при возрастании толщины эпитаксиальных слоев разбавленных полупроводников из-за наличия атомов магнитной примеси в кристаллической решетке происходит увеличение внутренних напряжений, обусловленных значительной разницей в параметрах кристаллических решеток немагнитной матрицы и магнитного эпитаксиального слоя. Для решения этой проблемы в последние годы получили развитие исследования гетероструктур, в которых магнитная примесь присутствует в виде ультратонкого слоя ( $\delta$-слоя) в объеме полупроводниковой матрицы $[4,5]$. Для изучения такого рода объектов авторами настоящей работы была разработана методика создания $\delta$-слоя марганца различной концентрации вблизи квантовой ямы в гетероструктурах на основе соединений GaAs [6]. Применение методики $\delta$-легирования позволяет получать как низкую, так и высокую концентрацию магнитной примеси в масштабах области, соизмеримой с постоянной решетки матрицы. Использование $\delta$-легирования на основе соединений марганца выявило упорядочение локализованных магнитных моментов в полупроводниковых гетероструктурах на основе соединений $\mathrm{A}^{\mathrm{III}} \mathrm{B}^{\mathrm{V}}$. Изменение характера распределения атомов марганца приводит к фазовому переходу полупроводник-металл и проявлению ферромагнетизма в слабых магнитных полях [5]. В настоящей работе мы рассмотрим влияние концентрации магнитной примеси в $\delta$-слое на магнитные и магнитотранспортные свойства, а также на формирование магнитного упорядочения в полупроводниковых наногетероструктурах с двумя спин-зависимыми подсистемами. 


\section{2. Структуры для исследований и методика экспериментов}

Гетероструктуры GaAs:Be/InGaAs/GaAs/ $\delta$-Mn/GaAs, содержащие одиночную квантовую яму шириной $10 \mathrm{~nm}$ и $\delta$-слои марганца различной концентрации, были получены на монокристаллической подложке $\mathrm{GaAs}(001)$ методом молекулярно-пучковой эпитаксии (МПЭ). Эпитаксиальное наращивание осуществлялось в едином технологическом процессе в ростовой камере Riber $\mathrm{C} 21$ в двух температурных диапазонах: $500-600^{\circ} \mathrm{C}$ и $200-250^{\circ} \mathrm{C}$. Полученные $\delta$-слои марганца располагались в верхнем, ближнем к поверхности образца, барьерном слое на расстоянии $3 \mathrm{~nm}$ (толщина буферного слоя $\mathrm{GaAs}$ ) от квантовой ямы на основе соединения $\mathrm{Ga}_{0.84} \mathrm{In}_{0.16}$ As. В настоящей работе рассмотрены $\delta$-слои марганца в интервале толщин 0.4-2 монослоя (МС). Нижний, ближний к подложке, барьерный слой GaAs легировался немагнитной акцепторной примесью бериллия для обеспечения заполнения квантовой ямы дырками. В результате в исследуемых гетероструктурах существуют одновременно два близких друг к другу канала носителей тока - квантовая яма, обогащенная дырками, и $\delta$-слой магнитной примеси.

Послойный анализ полученной гетероструктуры производился с помощью метода вторичной ионной масс-спектрометрии (ВИМС). Исследования проводились с использованием ионного микрозонда ims-6f, фирмы Сатеса (Франция). Следует отметить, что профиль $\delta$-слоя, вставленного в полупроводниковую матрицу, может размываться из-за взаимной диффузии атомов, так что толщина буферного слоя становится того же порядка, что и типичная ширина размытого $\delta$-слоя. На рис. 1 показаны концентрационные профили распределения индия (отвечает положению квантовой ямы

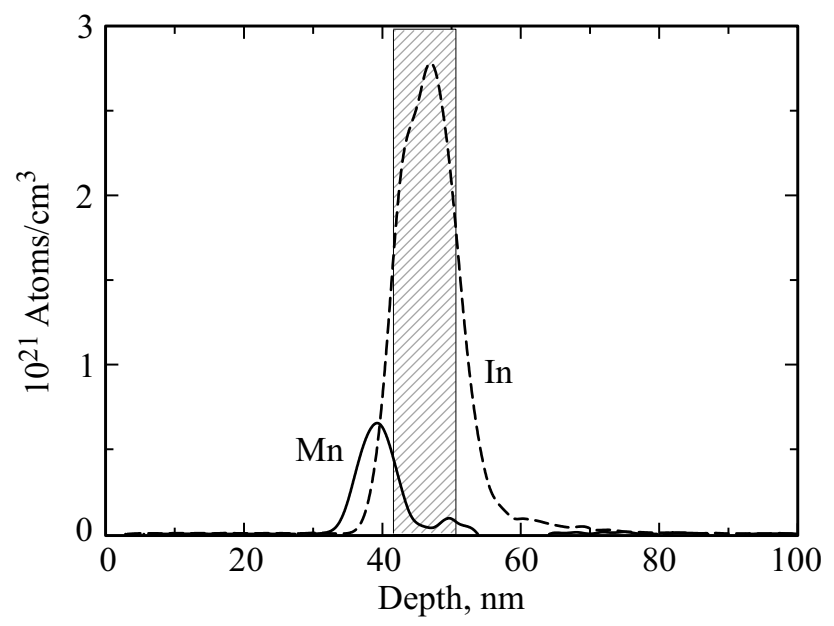

Рис. 1. Концентрационные профили индия (пунктирная кривая) и марганца (сплошная кривая) в гетероструктуре $\mathrm{GaAs}: \mathrm{Be} / \mathrm{Ga}_{0.84} \mathrm{In}_{0.16} \mathrm{As} / \mathrm{GaAs} / \delta$-Mn/GaAs. Заштрихованный прямоугольник показываем положение квантовой ямы $\mathrm{GaAs} / \mathrm{Ga}_{0.84} \mathrm{In}_{0.16} \mathrm{As} / \mathrm{GaAs}$.

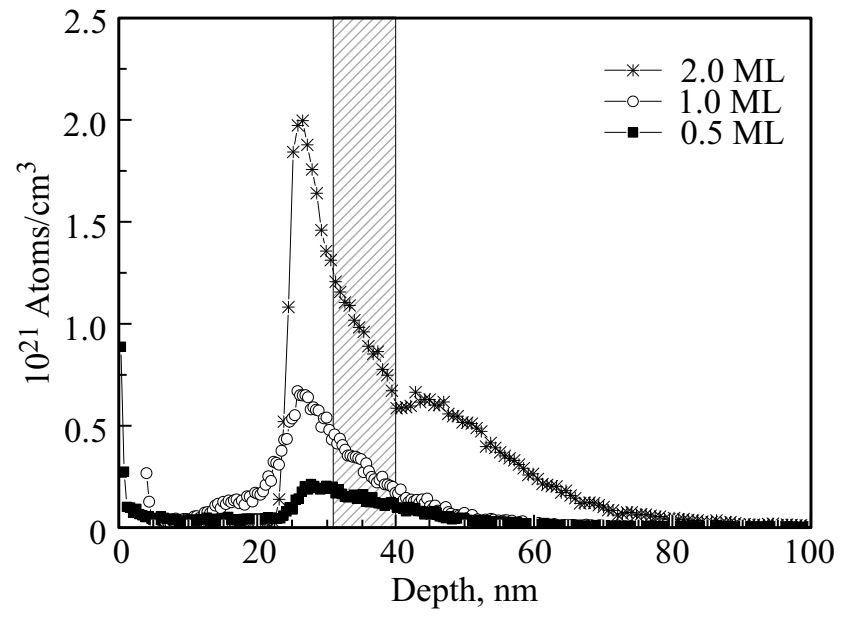

Рис. 2. Экспериментальные профили ВИМС марганца с концентрацией $0.5,1.2$ и $2 \mathrm{MC}$, полученные вдоль направления эпитаксиального роста. Нулевая отметка указывает на положение границы раздела воздух/поверхность гетероструктуры.

$\mathrm{GaAs} / \mathrm{Ga}_{0.84} \mathrm{In}_{0.16} \mathrm{As} / \mathrm{GaAs}$ ) и марганца, которые получены согласно методике, представленной в работе [6].

Толщина около $3 \mathrm{~nm}$ буферного слоя между $\delta$-слоем $\mathrm{Mn}$ и слоем трехкомпонентного твердого раствора GaInAs, по-видимому, является критической для диффузии марганца в квантовую яму GaAs/InGaAs/GaAs. Если при количестве марганца $0.4 \mathrm{MC}$ магнитная примесь локализована вблизи квантовой ямы и диффузия вглубь нее существенно ограничена, то при увеличении количества марганца в $\delta$-слое возможно проникновение атомов марганца в квантовую яму (рис. 2). Асимметрия экспериментального профиля ВИМС для распределения марганца в матрице демонстрирует в большей мере влияние аппаратного эффекта при травлении ионами высокой энергии. Диффузия марганца в квантовую яму зафиксирована только для образцов со слоями толщиной 2 МС. Следует отметить, что при малых концентрациях магнитной примеси верхний барьерный слой визуально не отображает какого-либо присутствия вставленного слоя другого состава, отличного от матричного материала. Линия контраста, которая могла бы быть приписана положению $\delta$-слоя, появляется на изображении, полученного с помощью просвечивающего электронного микроскопа, при толщинах слоев свыше 1.2 МC [7]. Это означает, что граница раздела между буферным слоем GaAs и последующим покрывающим слоем GaAs не псевдоморфна. На поверхности раздела становится заметным формирование структурных дефектов, индуцированных большой разницей постоянных кристаллических решеток между матричным материалом GaAs и сплавом MnAs c решеткой цинковой обманки [8].

Измерения температурных и полевых зависимостей удельного сопротивления и сопротивления Холла проводились на постоянном токе с использованием четырехконтактного метода на установке для измерения гальва- 
номагнитных эффектов в лаборатории полупроводников и полуметаллов и на установке PPMS-9 в ЦКП „Испытательный центр нанотехнологий и перспективных материалов“" (ИФМ УрО РАН). Контакты для всех образцов были подготовлены методом мокрого травления с использованием установки фотолитографического совмещения. Магнитные измерения (температурные и полевые зависимости статического магнитного момента) проведены в ЦКП „Испытательный центр нанотехнологий и перспективных материалов“ на СКВИД-магнитометре MPMS-5-XL (Quantum Design Co.). Температурный интервал измерений составлял $1.8-300 \mathrm{~K}$. Регулируемая величина магнитного поля $B$ устанавливалась в пределах до 5 Т. По измерениям статического магнитного момента образцов определяли намагниченность $M$ и статическую магнитную восприимчивость $\chi=M / B$. Температурные зависимости намагниченности $M$ определены для одного режима проведения эксперимента (FC), при котором измерение магнитного момента производилось в процессе охлаждения образца в измеряемом поле.

\section{3. Экспериментальные результаты и обсуждение}

Дырочный канал проводимости в изучаемых объектах образуется благодаря заполнению дырками квантовой ямы $\mathrm{GaAs} / \mathrm{InGaAs} / \mathrm{GaAs}$ из нижнего барьерного слоя $\mathrm{GaAs}$, легированного акцепторной примесью бериллия. В валентной зоне создаются проводящие подсистемы с концентрацией носителей тока порядка $7 \cdot 10^{13} \mathrm{~cm}^{-2}$, определенной при измерениях магнитополевых зависимостей продольного сопротивления $R_{x x}(B)$ и сопротивления Холла $R_{x y}(B)$ (рис. 3). Монотонное возрастание $R_{x x}(B)$ и $R_{x y}(B)$ в слабых магнитных полях (до $5 \mathrm{~T}$ ) для образца с $0.4 \mathrm{MC}$ марганца имеет характер линейной зависимости от поля, тогда как увеличение толщины $\delta$-слоя до значений более $1.2 \mathrm{MC}$ приводит к отклонению от линейности (рис. $3, a$ ). Это отклонение объясняется вкладом аномальной составляющей холловского сопротивления, вызванной намагниченностью магнитного слоя.

Сравнительный анализ $R_{x x}(B)$ и $R_{x y}(B)$ для гетероструктур с толщинами $\delta$-слоев марганца $0.4 \mathrm{MC}$ и $1.2 \mathrm{MC}$ позволил установить, что подвижность в обоих случаях слабо зависит от напряженности магнитного поля (см. вставку на рис. 3, $b$ ). Кроме того, подвижность в образце с $1.2 \mathrm{MC}$ была почти в два раза больше, чем в образце с $0.4 \mathrm{MC}: \mu_{12} \cong 70 \mathrm{~cm}^{2} / \mathrm{V} \cdot \mathrm{s}$ и $\mu_{04} \cong 35 \mathrm{~cm}^{2} / \mathrm{V} \cdot \mathrm{s}$ соответственно. Если считать, что при толщине $0.4 \mathrm{MC} \delta$-слой представляет собой не сплошной массив, а объединение кластеров, то возможно рассеяние электронов проводимости на интерфейсах образованных кластеров. С увеличением концентрации марганца и, соответственно, степени заполнения пространства между первоначально образованными кластерами изменяется величина проводимости гетероструктуры в
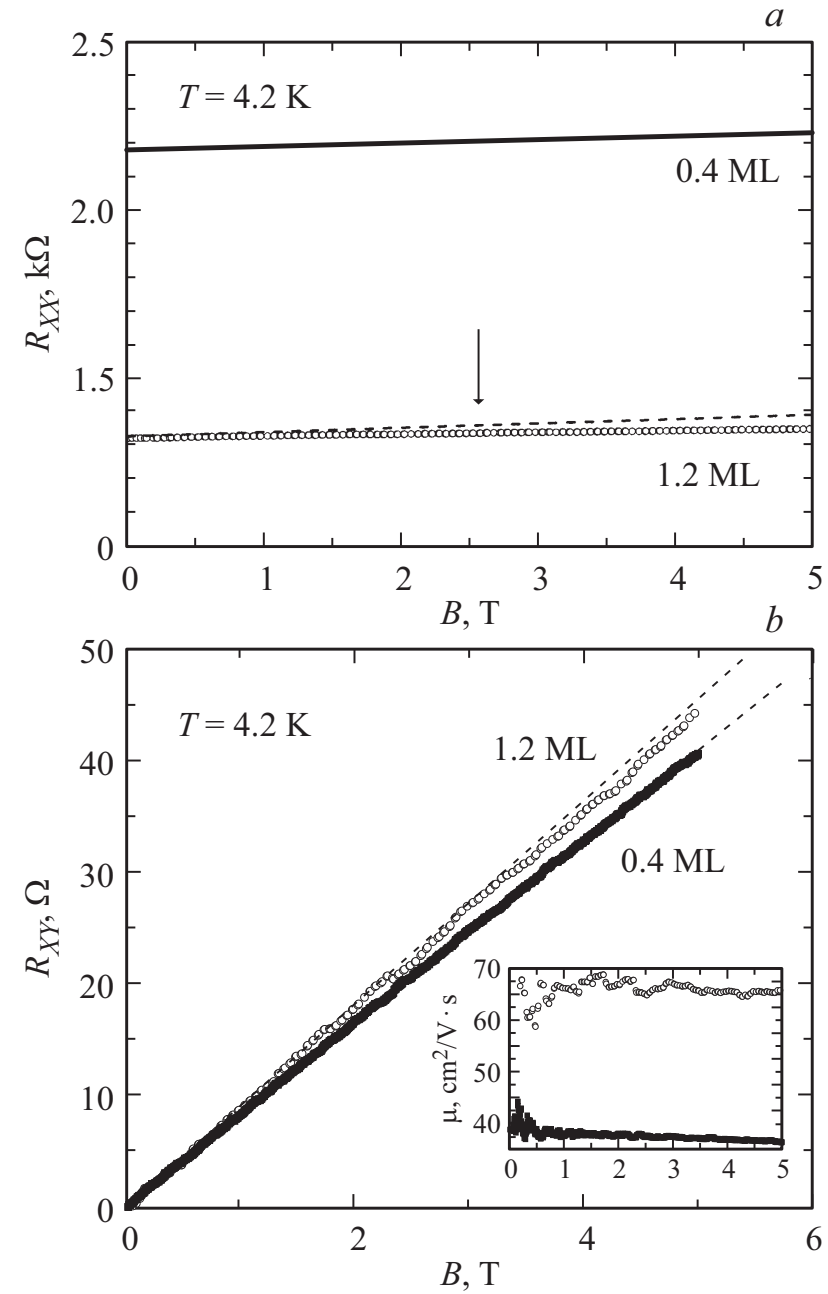

Рис. 3. Зависимости продольного сопротивления $(a)$ и сопротивления Холла $(b)$ от внешнего магнитного поля для гетероструктур $\mathrm{GaAs}: \mathrm{Be} / \mathrm{Ga}_{0.84} \mathrm{In}_{0.16} \mathrm{As} / \mathrm{GaAs} / \delta$-Mn/GaAs с $\delta$-слоем марганца различной концентрации при температуре $T=4.2 \mathrm{~K}$. На вставке на части $(b)$ приведены зависимости подвижности от магнитного поля.

целом. Увеличение концентрации вводимого примесного материала, по нашему мнению, позволяет получить слои толщиной в $0.3 \mathrm{~nm}$ (1 MC), которые будут упруго напряжены в силу малости своего размера, и уменьшить эффект кластеризации в самом $\delta$-слое. На рис. 3, $a$ показано, что увеличение концентрации марганца приводит к уменьшению сопротивления образца, то есть возрастанию вклада $\delta$-слоя в продольную проводимость на фоне проводящей системы дырок в квантовой яме. Величина продольного сопротивления при комнатной температуре для гетероструктур с $\delta$-слоем марганца составила $R_{04}=2.6 \mathrm{k} \Omega(0.4 \mathrm{MC}), R_{08}=1.6 \mathrm{k} \Omega(0.8 \mathrm{MC})$ и $R_{12}=1.1 \mathrm{k} \Omega(1.2 \mathrm{MC}$ ) (рис. 4$)$, что на два порядка меньше по сравнению с величиной $R_{\mathrm{Mn}}=680 \mathrm{k} \Omega$ для образцов со слоем разбавленного $\mathrm{Ga}(\mathrm{Mn}) \mathrm{As}$ (рис. 3 в работе [5]). Таким образом, появление проводящей подсистемы, включенной параллельно квантовой яме, 


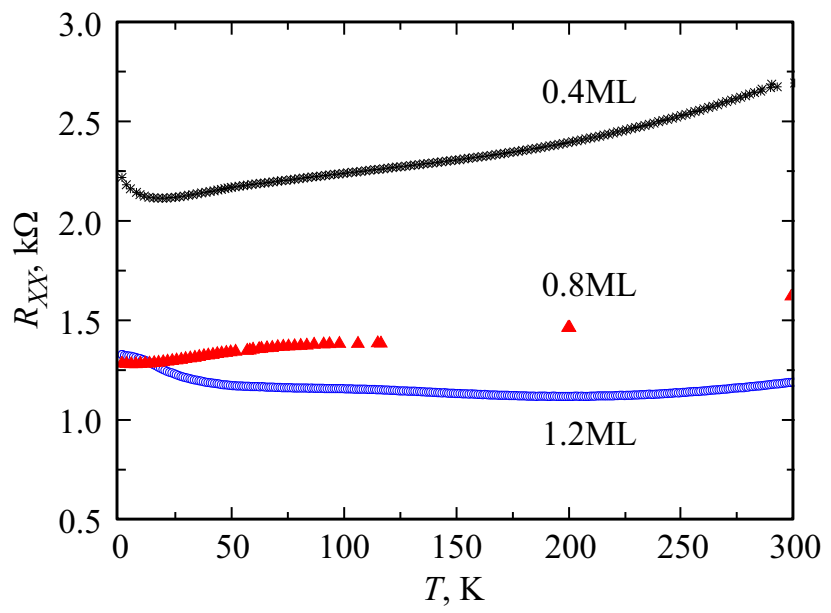

Рис. 4. Температурная зависимость продольного сопротивления гетероструктур $\mathrm{GaAs}: \mathrm{Be} / \mathrm{Ga}_{0.84} \mathrm{In}_{0.16} \mathrm{As} / \mathrm{GaAs} / \delta$ - Mn $/ \mathrm{GaAs}$ c $\delta$-слоем марганца различной концентрации.

привело к существенному падению общего сопротивления гетероструктуры.

Температурная зависимость продольного сопротивления $R_{x x}(T)$ исследуемых гетероструктур с $\delta$-слоем марганца оказалась существенно иной, чем у образца $\mathrm{GaAs} / \mathrm{Ga}_{0.84} \mathrm{In}_{0.16} \mathrm{As} / \mathrm{Ga}(\mathrm{Mn})$ As с барьерным слоем на основе разбавленного марганцем соединения. В отличие от активационной зависимости типа $R(T) \sim \exp (\Delta E / k T)$ с энергией активации $\Delta E \approx 50 \mathrm{meV}$ для образцов с разбавленным магнитным полупроводником [5], в гетероструктурах с толщиной $\delta$-слоев марганца до $1 \mathrm{MC}$ наблюдалось почти линейное изменение сопротивления $R_{x x}(T)$ при температурах выше $50 \mathrm{~K}$ (рис. 4). Однако, в интервале низких температур $T=1.8-30 \mathrm{~K}$ был зафиксирован рост $R_{x x}(T)$ пропорционально $\ln T$, что свидетельствовало о наличии слабой локализации носителей заряда в квантовой яме и двумерном характере проводимости. Особенностью температурной зависимости для гетероструктур с различной концентрацией марганца в $\delta$-слое является наличие широкого максимума в интервале температур $T=30-150 \mathrm{~K}$, который можно связать с проявлением магнитного упорядочения. Для гетероструктур с количеством марганца до $1 \mathrm{MC}$ наблюдаемый максимум выражен совсем слабо $(70 \mathrm{~K}$ для $0.8 \mathrm{MC}$ и $30 \mathrm{~K}$ для $0.4 \mathrm{MC}$ ), однако можно видеть, что его положение смещается в сторону больших значений температуры с увеличением толщины $\delta$-слоя, что может быть объяснено возрастанием намагниченности. Тогда можно оценить величину температуры Кюри $T_{C}$ при различных концентрациях магнитной подсистемы (например, $T_{C} \approx 100 \mathrm{~K}$ для гетероструктуры с $1.2 \mathrm{MC}$ ).

Результаты магнитных измерений гетероструктур $\mathrm{GaAs}: \mathrm{Be} / \mathrm{Ga}_{0.84} \mathrm{In}_{0.16} \mathrm{As} / \mathrm{GaAs} / \delta$-Mn/GaAs с $\delta$-слоем марганца различной концентрации представлены на рис. 5 и 6. Кривые намагничивания на рис. 5 демонстрируют существование магнитного упорядочения при тем- пературе $T=5 \mathrm{~K}$. Видно, что в гетероструктуре с толщиной слоя марганца $0.4 \mathrm{MC}$ в магнитном поле $B=0.4$ Т намагниченность насыщается и достигает значения $M=1.56 \cdot 10^{-4} \mathrm{emu} / \mathrm{g}$, тогда как в гетероструктурах с бо́льшей толщиной $\delta$-слоя марганца $(1.2 \mathrm{MC}$ и $2 \mathrm{MC}$ ) насыщение не наблюдается вплоть до $B=3 \mathrm{~T}$. Такое поведение намагниченности с ростом концентрации марганца может быть связано с проникновением атомов магнитной примеси из $\delta$-слоя в квантовую яму, которое влияет на характер взаимодействия между носителями заряда, препятствуя установлению магнитного упорядочения в слабых полях.

На рис. 6 представлены температурные зависимости магнитной восприимчивости $\chi(T)$, измеренной в поле $B=3$ Т. Магнитная восприимчивость всех образ-

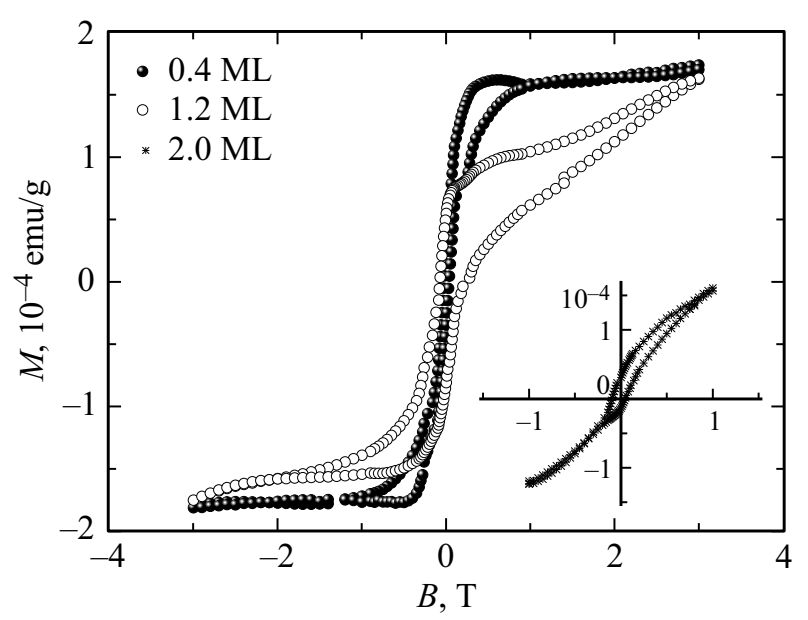

Рис. 5. Кривые намагничивания гетероструктур $\mathrm{GaAs}: \mathrm{Be} /$ $\mathrm{Ga}_{0.84} \mathrm{In}_{0.16} \mathrm{As} / \mathrm{GaAs} / \delta$-Mn/GaAs с $\delta$-слоем марганца различной концентрации.

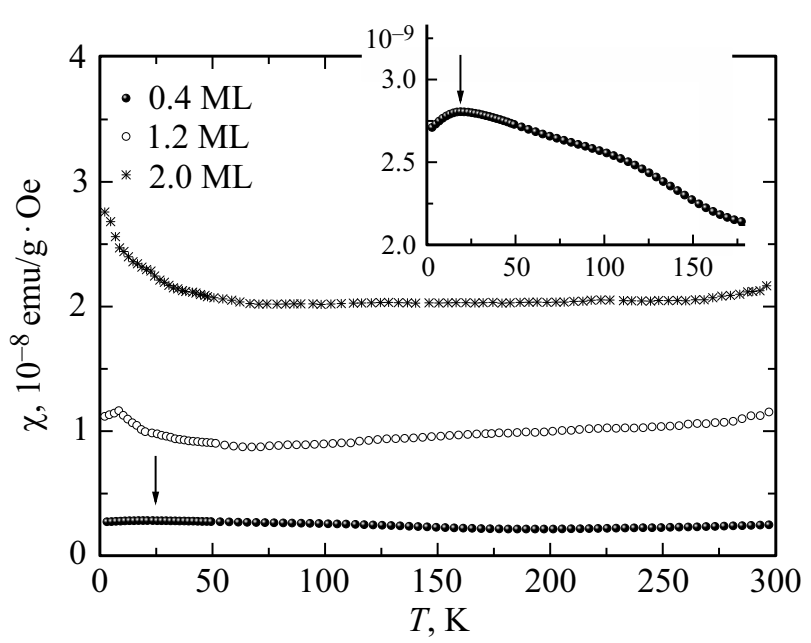

Рис. 6. Температурные зависимости магнитной восприимчивости гетероструктур GaAs: $\mathrm{Be} / \mathrm{Ga}_{0.84} \mathrm{In}_{0.16} \mathrm{As} / \mathrm{GaAs} / \delta$-Mn/GaAs с $\delta$-слоем марганца различной концентрации $(B=3 \mathrm{~T})$. На вставке - зависимость $\chi(T)$ для образца M490_0.4 МС в низкотемпературном интервале $(T<150 \mathrm{~K})$. 
Значения концентрации атомов Mn, магнитного момента насыщения, в расчете на один атом Мп ферромагнитной и парамагнитной температур Кюри $T_{N}$ и $\Theta$, парамагнитного момента, определенного из константы Кюри $(C)$, и отношения Вольфарта-Роудса $\mu_{p} / \mu_{S}$

\begin{tabular}{c|c|c|c|c|c|c|c}
\hline Толщина $\delta$-слоя & $N_{\mathrm{Mn}}$, at $/ \mathrm{cm}^{2}$ & $C, \mathrm{~cm}^{2} / \mathrm{g} \cdot \mathrm{K}$ & $\mu_{S}, \mu_{\mathrm{B}} /$ atom Mn & $T_{N}, \mathrm{~K}$ & $\Theta, \mathrm{K}$ & $\mu_{p}, \mu_{\mathrm{B}} /$ atom $\mathrm{Mn}$ & $\mu_{p} / \mu_{S}$ \\
\hline $0.4 \mathrm{MC}$ & $1.19 \cdot 10^{14}$ & $8.47 \cdot 10^{-8}$ & 6.2 & 23 & -200 & 3.8 & 0.6 \\
$1.2 \mathrm{MC}$ & $3.55 \cdot 10^{14}$ & $8.41 \cdot 10^{-8}$ & 1.1 & 8.3 & -58 & 1.6 & 1.4 \\
$2 \mathrm{MC}$ & $5.92 \cdot 10^{14}$ & $1.58 \cdot 10^{-7}$ & 2.5 & - & -15 & 3.3 & 1.3
\end{tabular}

цов в широких температурных интервалах $(0.4 \mathrm{MC}-$ $100-200 \mathrm{~K}, 1.2 \mathrm{MC}-10-60 \mathrm{~K}, 2 \mathrm{MC}-10-65 \mathrm{~K})$ следует закону Кюри-Вейсса $\chi(T)=C /(T-\Theta)$. С помощью аппроксимации линейных участков зависимостей $1 / \chi(T)$ определена константа Кюри $C$ и парамагнитная температура Кюри-Вейсса $\Theta$ (см. таблицу). Для всех образцов параметр $\Theta$ отрицателен, что отвечает возможности упорядочения антиферромагнитного типа. На зависимостях $\chi(T)$ наблюдаются максимумы вблизи температуры фазового перехода $T_{N}$ (указаны стрелками на рис. 6).

С использованием выражения для константы Кюри $C=N m_{p}^{2} \mu_{\mathrm{B}}^{2} / 3 k$, где $N-$ число магнитных атомов $(\mathrm{Mn})$, $\mu_{\mathrm{B}}-$ магнетон Бора, $k-$ постоянная Больцмана, получены значения эффективного магнитного момента $\mu_{p}$ для всех исследованных образцов (см. таблицу). Значение $\mu_{p}$ для образца с количеством марганца в $\delta$-слое $0.4 \mathrm{MC}$ близко к значению $\mu_{p}$ для образца с $2 \mathrm{MC} \mathrm{Mn} \mathrm{и} \mathrm{более} \mathrm{чем} \mathrm{в} \mathrm{два} \mathrm{раза} \mathrm{превышает} \mathrm{величину} \mu_{p}$ для образца толщиной с $1.2 \mathrm{MC}$. Значения магнитного момента насыщения $\mu_{S}$ при $T=5 \mathrm{~K}$, определенные по величине намагниченности насыщения, представлены в таблице. Величина $\mu_{S}$ для образца с $0.4 \mathrm{MC} \mathrm{Mn}$ имеет максимальное значение $\left(\mu_{S}=6.2 \mu_{\mathrm{B}}\right)$ среди всех исследованных образцов. Парамагнитная температура Кюри $\Theta=-200 \mathrm{~K}$ для этого же образца, характеризующая интенсивность обменного взаимодействия, также максимальна. Таким образом, характерные для антиферромагнетизма свойства проявляются в образце с минимальной толщиной $\delta$-слоя марганца $0.4 \mathrm{MC}$, что может быть связано с особенностями распределения марганца в слое, то есть с образованием кластеров марганца в процессе осаждения, тогда как увеличение концентрации марганца приводит к изменению магнитного упорядочения и созданию предпосылок для перехода в парамагнитное состояние. При этом в гетероструктуре с $0.4 \mathrm{MC}$ марганца в отличие от гетероструктур с толщиной $\delta$-слоя 1.2 и $2 \mathrm{MC}$ при изучении явления гистерезиса практически не наблюдалась остаточная намагниченность. Экспериментально определенное отношение $\mu_{p} / \mu_{S}$ для всех образцов оказалось порядка единицы (см. таблицу), что характерно для магнитоупорядоченных систем с локальными магнитными моментами $[9,10]$. Своеобразное поведение $\delta$-слоев марганца в полупроводниковой матрице в настоящее время достаточно активно обсуждается. Возможные фазовые переходы между ферромагнитным, парамагнит- ным и ферримагнитным состояниями в засисимости от концентрации магнитной примеси были рассмотрены в работах $[11,12]$.

\section{4. Результаты и выводы}

Показано, что в гетероструктурах на основе арсенида галлия $\mathrm{GaAs}: \mathrm{Be} / \mathrm{Ga}_{0.84} \mathrm{In}_{0.16} \mathrm{As} / \mathrm{GaAs} / \delta$ - Mn/GaAs проводимость в квантовой яме сильно зависит от концентрации атомов марганца в $\delta$-слое. Такой эффект объясняется гибридизацией состояний локализованных носителей тока с электронными состояниями $\delta$-слоя марганца. Изучение магнитных свойств данных гетероструктур показало существование магнитного упорядочения, возникающего при различной концентрации магнитной примеси, при этом было продемонстрировано весьма значительное и сложное разнообразие характера упорядочения. Магнитное упорядочение слоя подтверждено наблюдением гистерезиса кривых намагничивания, обнаружены свидетельства существования спонтанного магнитного упорядочения примесной системы, а также большого различия вкладов для $\delta$-слоев с низким и высоким содержанием примесей в сопротивление, которое связано с особенностями рассеяния носителей тока в системах с различной концентрацией примесей. Наряду с металлическим состоянием в исследуемых гетероструктурах имеет место антиферромагнетизм в образцах с низкой концентрацией марганца в $\delta$-слое (отрицательная температура Кюри) и обнаружено проявление более сложного типа магнитного упорядочения при увеличении концентрации марганца. Таким образом, гетероструктуры с разным содержанием атомов магнитных примесей, локализованных в достаточно ограниченной области полупроводниковой матрицы, по своим магнитным и проводящим свойствам существенно отличаются друг от друга, что требует дальнейшего изучения как магнитных, так и транспортных свойств данных структур.

Авторы благодарят М. Лопеса-Лопеса (Национальный политехнический институт - СИНВЕСТАВ, Мексика) за предоставленные гетероструктуры и А.Ф. Губкина (ИФМ УрО РАН, Екатеринбург) за помощь в проведении измерений магнитных свойств на установке MPMS-XL-5. 


\section{Список литературы}

[1] H. Ohno, A. Shen, F. Matsukura, A. Oiwa, A. Endo, S. Katsumoto, Y. Iye. Appl. Phys. Lett. 69, 363 (1996).

[2] F. Matsukura, H. Ohno, T. Dietl. III-V Ferromagnetic Semiconductors, Handbook of Magnetic Materials 14 / Ed. K.H.J. Buschow. Elsevier, Amsterdam (2002). P. 1-87.

[3] T. Dietl, H. Ohno. Rev. Mod. Phys. 86, 187 (2014).

[4] A.M. Nazmul, T. Amemiya, Y. Shuto, S. Sugahara, M. Tanaka. Phys. Rev. Lett. 95, 017201 (2005).

[5] А.М. Луговых, Т.Б. Чарикова, В.И. Окулов, К.Д. Моисеев, Ю.А. Кудрявцев. ФТТ 58, 2160 (2016).

[6] К.Д. Моисеев, В.Н. Неведомский, Yu. Kudriavstev, А. Escobosa-Echavarria, M. Lopez-Lopez. ФТП 51, 1189 (2017).

[7] A.M. Nazmul, S. Sugahara, M. Tanaka. J. Cryst. Growth 251, 303 (2003).

[8] M. Shirai, T. Ogawa, I. Kitagawa, N. Suzuki. J. Magn. Magn. Mater. 177, 1383 (1998).

[9] В.Ю. Ирхин, М.И. Кацнельсон, УФН 164, 705 (1994).

[10] Т. Мория, Спиновые флуктуации в магнетиках с коллективизированными электронами Мир, М. (1988).

[11] V.N. Men'shov V.V. Tugushev, S. Caprara, P.M. Echenique, E.V. Chulkov. Phys. Rev. B 80, 035315 (2009).

[12] S. Caprara, V.V. Tugushev, E.V. Chulkov. Phys. Rev. B 84, 085311 (2011).

Редактор Е.Ю. Флегонтова 